\title{
Core Stability
}

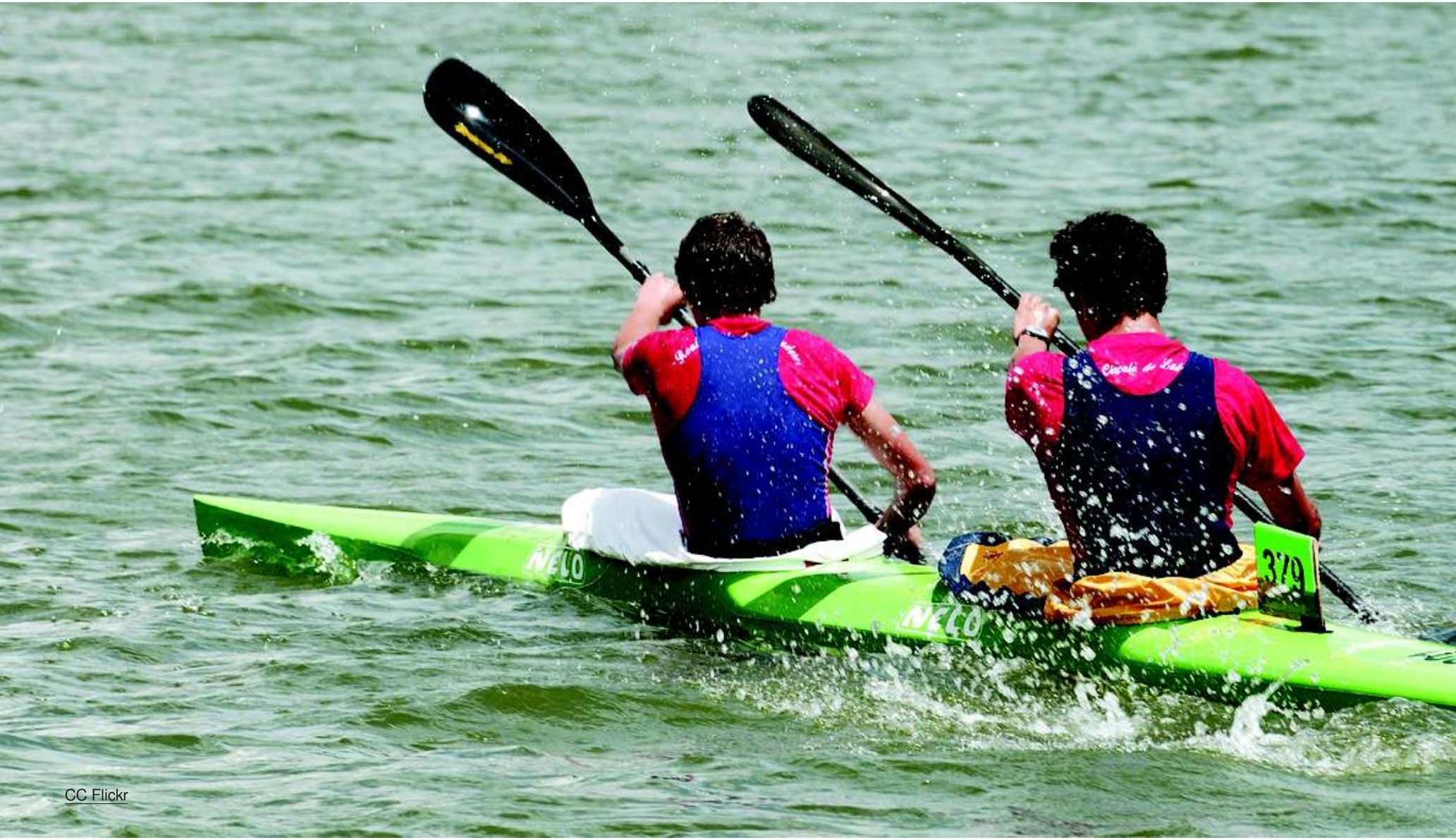

Estudios

preliminares sobre

biomecánica

relacionan la

estabilidad del

tronco con un mejor

rendimiento

deportivo

- Alicia de Lara

I I principal problema a la hora de me- dir la estabilidad del tronco parte de - la ambigüedad en torno al concepto, sobre todo en ámbitos del entrenamiento y la medicina deportiva. Por su parte, las revistas científicas también reflejan controversia. El hecho de que se entienda el mismo término de forma distinta lleva a un abanico de test de campo muy diferentes y poco precisos. Como expone el director de Grupo de Investigación en Biomecánica para la Salud y Rendimiento Deportivo, Francisco Vera García, la estabilidad es dependiente del contexto y la mayoría de estas pruebas no la miden realmente, sino que se centran en variables asociadas, como pueden ser la fuerza o la resistencia.

El grupo de investigación ha analizado los test que se utilizan comúnmente para medir la estabilidad en los gimnasios y ha comprobado que los datos no concuerdan con los obtenidos en el laboratorio. En tal caso, ia qué se alude realmente cuando se habla de estabilidad del tronco? Vera García explica que, desde el ámbito de la biomecánica, se entiende por estabilidad a la capacidad de mantener una postura o una trayectoria determinada, a pesar de las fuerzas existentes. A su juicio, en los gimnasios o clubes han desarrollado un concepto de core stability que se aleja de la realidad: "Si decimos que la estabilidad lumbar es igual a la fuerza, al control o a la resistencia, al final, todo lo que tenga relación con el tronco acabará siendo estabilidad, y eso no es preciso". "Para medirla hay que retar a la columna aplicándole fuerzas y comprobar cómo responde, si recupera rápidamente la posición o la trayectoria", matiza el profesor.

Para ello, el grupo ha desarrollado dos técnicas que permiten medir diversas variables implicadas en la estabilidad, por ejemplo, la respuesta del tronco ante fuerzas súbitas. Mediante un modelo matemático, el equipo establece la rigidez del tronco y el amortiguamiento, en relación a variables como el desplazamiento angular, el momento de fuerzas aplicado, la masa, la altura u otra serie de características personales. "Aplicamos fuerza a través de un percutor neumático al individuo, quien tiende a desequilibrarse en distintas direcciones mientras permanece sentado", explica Vera García. Según el director, para llevar a cabo la prueba en dinámico, el asiento donde se ejercen las fuerzas es móvil e impide que los pies del sujeto toquen el suelo: "Se trata de una 
